\title{
LA ORIENTACIÓN ESCOLAR EN EL PROCESO DE ENSEÑANZA - APRENDIZAJE DE LAS CIENCIAS NATURALES ${ }^{1}$
}

\author{
THE SCHOOL GUIDANCE IN THE TEACHING-LEARNING PROCESS OF NATURAL SCIENCES \\ A ORIENTAÇÃO ESCOLAR NO PROCESSO DE ENSINO - APRENDIZAGEM DAS CIÊNCIAS \\ NATURAIS \\ Ramiro Ruiz Fuentes ${ }^{2}$
}

Fecha de Recibido: Agosto 01 de 2016 | Fecha de Aprobado: Septiembre 22 de 2016

\begin{abstract}
Resumen
Las propias características de cómo el maestro debe hacer llegar el conocimiento y cómo los alumnos pueden apropiarse de él, permiten identificar a la orientación escolar como sustento básico para la mejora, cuestión que se requiere en la actualidad en materias de elevada dificultad, como las que se adscriben a las Ciencias Naturales. El presente artículo refleja de forma concreta, aspectos teóricos y metodológicos esenciales de la orientación escolar como proceso válido para dinamizar la enseñanza y el aprendizaje en general, y de las Ciencias Naturales en particular.
\end{abstract}

Palabras clave: Orientación educativa, orientación escolar, enseñanza y aprendizaje, objeto de aprendizaje.

1 Artículo corto.

2 Licenciado en Educación, Especialidad Química. Profesor Asistente. Universidad de Holguín, Cuba. Maestrante del programa de Orientación Educativa. Correo electrónico: robbincabezaruiz@gmail.com 


\section{Abstract}

The appropriate characteristics of how teacher must transmit the knowledge and how students can take it permit to define the school guidance as basic support for the improvement. This matter is required at present in high difficulty subjects such as those assigned to natural sciences. This article reflects in particular, indispensable theoretical and methodological aspects of the school guidance as a valid process to strengthen teaching and learning in general, as well as natural sciences.

Keywords: Educative guidance, school guidance, teaching and learning, objectof learning.

\section{Resumo}

As próprias características de como o maestro deve fazer chegar o conhecimento e como os alunos podem ser apropriado dele, permitem identificar à orientação escolar como sustento básico para a melhora, questão que se requer na atualidade em matérias de elevada dificuldade, como as que se adscriben às ciências naturais. 0 presente artigo reflete de forma concreta, aspectos teóricos e metodológicos essenciais da orientação escolar como processo válido para dinamizar o ensino e a aprendizagem em general, e das ciências naturais em particular.

Palavras chave: Orientação educativa, orientação escolar, ensino e aprendizagem, objeto de aprendizagem. 


\section{INTRODUCCIÓN}

Existe coincidencia por parte de diferentes investigadores como (Domínguez, 1995), (Pérez, 2007), (Parra, 2009), (Sanchiz, 2009) acerca de la Orientación Educativa como la "relación de ayuda (proceso interactivo) que se establece entre el orientador y el orientado (individuo o grupo)". Sus orígenes se identifican de manera independiente en los Estados Unidos de Norteamérica y Europa, durante los albores de siglo XX, y como consecuencia del movimiento reivindicativo de reformas sociales y la necesidad de capacitar a la fuerza de trabajo, fundamentalmente joven, para asumir el creciente desarrollo tecnológico e industrial, por medio de una orientación profesional.

Este fenómeno impulsó el estudio y posterior tratamiento de las características de las personas para desempeñarse en diferentes puestos de trabajo, al tiempo que los procesos de ayuda, consistentes en el intercambio durante largas horas entre el orientador y el orientado en función del mejoramiento del rendimiento académico y la disciplina, se introdujeron con mayor intencionalidad en la escuela y otros contextos, con el fin de contribuir a la formación integral de la personalidad de todos los ciudadanos.

De este modo, la orientación educativa comenzó a abarcar nuevos contenidos relacionados no solamente con la ayuda encaminada a la capacitación para una futura profesión (orientación profesional), dando lugar al desarrollo de la orientación personal, la orientación escolar, la orientación familiar y la orientación sexual. Estas temáticas de conocimiento se distinguen como partes de la orientación educativa y son consideradas como áreas de orientación (Sanchiz, 2009).

La orientación escolar es considerada una de las áreas prioritarias de actuación de la orientación educativa (Parra, 2009), teniendo en cuenta los continuos cambios y las crecientes necesidades que caracterizan la práctica educativa en correspondencia con las variables demandas de la sociedad; al mismo tiempo, el accionar en esta área de orientación se encuentra en estrecha relación con las teorías de aprendizaje que se asuman, las características del educando y el contexto escolar, así como con el resto de las áreas de orientación educativa.

En la enseñanza de las Ciencias Naturales, se han puesto en práctica experiencias, tanto en el contexto internacional como nacional, dirigidas a orientar al estudiante para superar los diferentes problemas de aprendizaje a los cuales se enfrenta (Fernández, 2007), (Pérez, 2007), (Bernaza, 2011), (López 2011).

\section{ANTECEDENTES}

La orientación escolar, también denominada como orientación académica o para el aprendizaje, constituye, a decir de Sánchez (2009), una de las áreas fundamentales de orientación; la misma estudia los conocimientos, teorías y principios que facilitan los procesos de aprendizaje, refiriéndose a temas como hábitos y técnicas de estudio, las habilidades y las estrategias de aprendizaje así como a las dificultades en este proceso.

El surgimiento de la orientación escolar constituye fruto del propio desarrollo de la orientación educativa, pues, aunque esta surge como una actividad ajena a la escuela, a partir de los primeros años del siglo XX, tanto en Estados Unidos como en Europa, se convirtió en una actividad escolar dirigida a orientar vocacional y profesionalmente a los alumnos, evitando así que abandonaran los estudios sin la adecuada preparación para enfrentarse al mundo laboral. De esta forma, la orientación profesional se apoyó cada vez más en la orientación para el aprendizaje, de manera que la orientación escolar constituyó el área más favorecida entre los años 30 y la segunda guerra mundial (García, 2014).

Según Pérez (2007), la orientación escolar tiene como centro la asistencia al estudiante, surge con el fin de que este aumente su rendimiento académico y encuentre soluciones a los problemas de aprendizaje. Se desarrolla a partir de la corriente psicométrica.

Con las disímiles particularidades propias de los diferentes contextos en los cuales se desenvuelven, son reconocidos los aportes sobre orientación educativa, y escolar en particular de autores como Bisquerra (2005), Repetto (2006), Muñoz (2004), Torres (2005) y Molina (2005). En Cuba, se destacan las investigaciones de Calviño, M. (1996), Del Pino (1999), Díaz Cantillo (2001), Cubela, (2005), García (2006) y Recarey (2006). Estos autores cubanos coinciden en concebir la orientación escolar relacionada con el resto de las áreas, acorde a la corriente integrativa de orientación.

Para Nerici (1990) la orientación escolar constituye un proceso educativo, a través del cual se asiste 
al educando con el fin de que este pueda obtener pleno rendimiento en sus actividades escolares.

De igual modo para Ayala (1998), la orientación escolar implica "un proceso de asesoramiento continuo en el que el docente promueve actividades de tipo preventivo, dirigidas a la formación de hábitos de estudio, atención y concentración en clase, aprovechamiento del tiempo y desarrollo de habilidades cognitivas".

Por su parte, Torres (2005) asume la orientación escolar como un proceso continuo e integrado en la actividad de enseñanza-aprendizaje, mediante la cual el docente atiende las necesidades individuales y grupales, con la cooperación de todos los miembros de la comunidad educativa.

Para Repetto (2006), la orientación escolar es la ayuda que se presta al orientado para que su aprendizaje intelectual sea eficiente e individualizado, esta persigue que el estudiante alcance el máximo rendimiento académico posible. Para alcanzar esta meta, el orientador debe imbricar tres sectores: el alumno, los profesores y el currículum.

En resumen, estos autores consideran que la orientación escolar debe contribuir a facilitar el proceso de adquisición de contenidos por parte del alumno, así como al conocimiento de los factores que inciden en el rendimiento académico y al asesoramiento para la prevención del fracaso escolar; abogan incluso, porque la orientación forme parte de los planes y programas de las escuelas, ya que el aprendizaje de los alumnos es una de las principales razones de ser de los centros educativos.

Aunque los contenidos de la Orientación en el ámbito de los procesos de enseñanza y aprendizaje no se han definido de un modo preciso y unánime, Vélaz de Medrano (1998) como se citó en Sanchiz (2009) establece cinco tipos de programas que pueden llevar a cabo los orientadores y orientadoras para contribuir a mejorar los procesos de enseñanza-aprendizaje:

- Desarrollo de hábitos y técnicas de trabajo intelectual

- Adquisición de técnicas de estudio

- Desarrollo de estrategias meta cognitivas aplicadas al estudio

- Desarrollo cognitivo

- Motivación

En cuanto a la relación de la orientación con el proceso enseñanza-aprendizaje, resulta interesante la propuesta de Pérez (2007) quien logra precisar las potencialidades de los componentes del proceso para la orientación educativa, es decir: problema, objetivo, contenido, método, medio de enseñanza, evaluación y formas de organización.

Por su parte, López (2012) profundiza en la importancia de la orientación para la realización de tareas docentes integradoras y plantea que la función orientadora del profesor no se limita a la asignación de la tarea docente integradora, sino que continúa durante toda su solución a través de niveles de ayuda a los estudiantes acorde con sus particularidades individuales.

En correspondencia con el proceso de enseñanza aprendizaje de las ciencias naturales, se destacan las investigaciones de Bernaza (2011), quien demuestra la importancia de la orientación escolar en función de lograr determinar el contenido concreto de las acciones que debe ejecutar el sujeto para alcanzar el objetivo previsto y satisfacer su necesidad, la misma abarca desde la percepción hasta el pensamiento.

La comprensión de la situación transita por:

- Análisis de la situación.

- Distinción del objeto de aprendizaje y el objetivo a lograr, el conocimiento renovado.

- Esclarecimiento de la vía (las acciones concretas) para alcanzar el objetivo.

- Control y corrección, regulación de la acción a lo largo de la ejecución.

Este autor enfatiza sobre la importancia de que el estudiante reflexione sobre cómo aprendió, cómo construyó o utilizó las vías para llegar al resultado esperado y cómo elaboró sus propias herramientas de aprendizaje, para hacerlo más consciente y perfeccionarlo. Además, ofrece una caracterización de la orientación del aprendizaje, proponiendo las características siguientes:

- Plenitud

- Generalidad

- Independencia

- Significado

- Carácter consciente

Del mismo modo menciona algunas acciones para la construcción de las orientaciones de aprendizaje, que tienen al estudiante como principal protagonista: 
- Identificación del objeto de aprendizaje.

- Diagnóstico del conocimiento previo del estudiante sobre el objeto de aprendizaje.

- Determinación de las vías para la construcción del objeto de aprendizaje.

- Identificación del contenido de cada una de las acciones para la construcción del objeto de aprendizaje.

- Ejecución de las acciones.

- Valoración de los resultados de la construcción.

- Reajuste de la construcción realizada.

\section{CONCLUSIONES}

En correspondencia con la corriente integrativa de orientación educativa, la orientación escolar consiste en ofrecer niveles de ayuda al estudiante para aprender a aprender, teniendo en cuenta la situación social de desarrollo, de manera que estimule las potencialidades para la satisfacción de las necesidades en el aprendizaje, favoreciendo su participación en la transformación social.

El proceso de enseñanza - aprendizaje de las ciencias naturales posee potencialidades para la orientación escolar, de manera que el docente pueda atender las necesidades individuales y grupales, en relación con las restantes áreas de orientación.

\section{REFERENCIAS}

Alfonso, I. (2016). ¿Por qué es necesaria la orientación educativa en la universidad de hoy?

Almaguer, A. (2011). Perspectiva de la orientación educativa como pilar del modelo cubano de universidad. En: Cuadernos de Educación y Desarrollo. Vol. 3, 27.

Ayala, A. (1998). La función de profesor como asesor. Barcelona.

Bisquerra, R. (1998). Modelos de Orientación e intervención psicopedagógica. Barcelona, Paris.

Bernaza, G. (2011). Directo a la diana: Sobre la orientación del estudiante para aprender. Revista Educación Cubana.

Domínguez, L. (1995). Material elaborado para la Maestría en Psicología Educativa de la Facultad de Psicología de la Universidad de La Habana.
Do Ceu, M. (2003). Guidance Theory and practice: the status of career exploration. British Journal of Guidance and Counselling, Vol 31, 2.

Ferrant, E. (2010). Apoyo de profesores y padres de familia en la formación de hábitos de estudio. Revista mexicana de orientación. Vol VII, 18.

Fernández, C. (2007). Los procesos de orientación escolar y la toma de decisiones académica y profesional. Revista Complutense de Educación. Vol. 18, 2.

García, A. (2014). Programas y alternativas de la orientación educativa en la escuela: Enfoques y experiencias en el desarrollo de la práctica. Evento Pedagogía provincial.

Guevara, G. (2012). La orientación educativa y familiar. Su implicación en la formación del profesional universitario en Cuba. Vol, 2.

López, F. (2011). Tareas docentes integradoras para la atención diferenciada a los estudiantes de secundaria básica: Una propuesta metodológica para el profesor. Tesis doctoral. UCPH.

Matas, A. (2007). Modelos de Orientación Educativa. Aidesoc.net.

Parras, A. (2009). Orientación educativa: Fundamentos teóricos, modelos institucionales y nuevas perspectivas. Secretaría General Técnica. España.

Pérez, R. (2007). Concepción de orientación educativa para el aprendizaje de la convivencia comunitaria en secundaria básica. Tesis doctoral. UCPH.

Repetto, E. (2008). Las competencias de los orientadores en Europa: fundamentos, desarrollo y conclusiones del proyecto EAS. En: s/ed. Jornadas Europeas El desarrollo profesional de los orientadores. Universidad de Educación a Distancia. Madrid.

Ruiz, Y. (2010). Los orígenes de la orientación educativa. Revista Temas para la Educación, 10.

Sánchez, G. (2014). La motivación hacia el aprendizaje en los estudiantes de la carrera Pedagogía-Psicología. Tesis doctoral. UCPH. 